\title{
Densely Calcified Pilocytic Astrocytoma in the Sellar/Suprasellar Region
}

\author{
Mahajan Manik a, c, Sharma Rajesh ${ }^{\mathrm{a}}$, Sharma Poonam ${ }^{\mathrm{b}}$, Gupta Anchal ${ }^{\mathrm{a}}$
}

\begin{abstract}
Pilocytic astrocytoma is a type of low grade glioma occurring mostly in children and adolescents. Thin calcifications may be seen within pilocytic astrocytomas. However dense calcifications are quite rare. We present the case of young boy presenting with densely calcified mass in the sellar/suprasellar region which was surgically excised and later on proved to be a pilocytic astrocytoma on histopathological analysis.
\end{abstract}

Keywords: Pilocytic Astrocytoma; Magnetic Resonance Imaging; Calcification; Craniopharyngioma

\section{Introduction}

Pilocytic astrocytoma is the most common paediatric central nervous system glial tumour. Pilocytic astrocytoma is a slowly growing, relatively circumscribed neoplasia that is classified by the World Health Organization (WHO) as grade I tumour [1]. It usually develops during the first two decades of life and it represents the most common cerebral tumour $(18 \%)$ in the paediatric age [2]. Pilocytic astrocytoma arises throughout the central nervous system but its most common locations are the cerebellum (80\%) and hypothalamic/optical pathways [1, 3]. Grossly, the tumors are cystic, with mural nodules in $50 \%$, and more solid with various cystic central

Manuscript accepted for publication October 4, 2012

a Department of Radio-diagnosis and Imaging, ASCOMS Hospital, University of Jammu, Jammu (J\&K), India

${ }^{\mathrm{b}}$ Department of Pathology, GMC Hospital, University of Jammu, Jammu (J\&K), India

${ }^{\mathrm{c} C}$ Corresponding author:Manik Mahajan, 39-A Extension, Gandhi Nagar, Jammu (J\&K), Pin-180004, India.

Email: manikmahajan20000@gmail.com

doi: http://dx.doi.org/10.4021/ijcp55w cavities in $40 \%$. Completely solid tumours comprise only $10 \%$ of the total. Only a minority of Pilocytic astrocytomas show calcification suggesting chronicity of the lesion. Also these calcifications are thin calcifications. We describe an unusual case of a 13 year old boy with sellar/suprasellar pilocytic astrocytoma with extensive calcifications.

\section{Case Report}

A 13 year old boy presented to the paediatric outpatient department of our hospital with chief complaints of headache and visual disturbance for the last 6 months. Headache was moderate in intensity, localized in frontal region, progressive in nature and was relieved only after taking medication Visual disturbances included diplopia and pain in the eyes. On physical and fundoscopic examination, no apparent abnormality could be made out. Patient was advised a CT scan of the head. Non contrast CT scan of head revealed an extensively calcified soft tissue density mass in the suprasellar region with dilatation of the lateral and third ventricles (Fig. 1). For further evaluation a MRI scan of the brain was done. MRI revealed an ill defined heterogeneously solid mass exhibiting hypointense signal on T1 weighted and hyperintense signal on $\mathrm{T} 2$ weighted images with a cystic component in the sellar/suprasellar region (Fig. 2, 3). Dilatation of the third and lateral ventricles was also seen. Post contrast images revealed intense heterogeneous enhancement of the lesion with non enhancing cystic component (Fig. 4). A diagnosis of craniophrayngioma was made on the basis of imaging features. Surgical excision of the tumour was done after two days. During the operation, the tumour was found to be yellowish white mass with moderate vascularity and dense calcifications. Gross total resection and histopathological examination of the specimen was performed. Upon histologic examination, the tumour manifested in a biphasic pattern composed of a combination of loose glial tissue punctuated by numerous microcysts and compact piloid tissue with elongated bipolar cells showing fibrillary hair-like processes, in addition to Rosenthal fibres (Fig. 5). These pathological features were consistent with a pilocytic astrocytoma. 


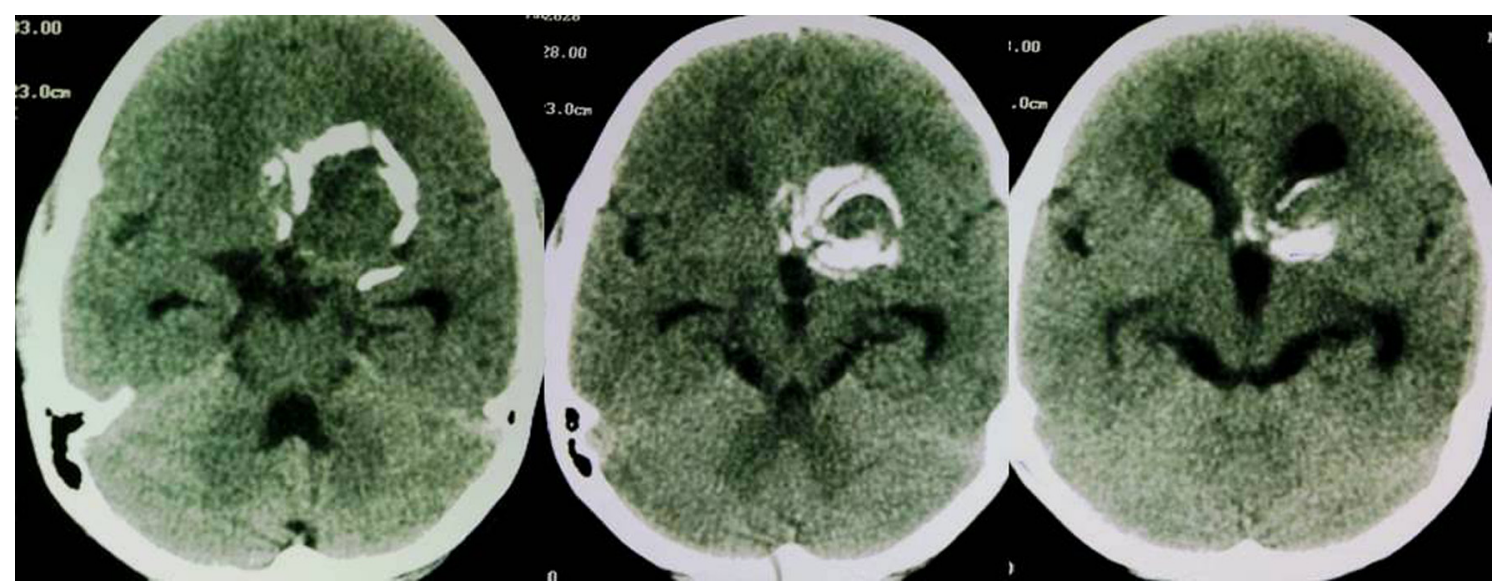

Figure 1. Axial non contrast CT images reveal a densely calcified soft tissue density lesion in the suprasellar region with associated dilatation of third and lateral ventricles.

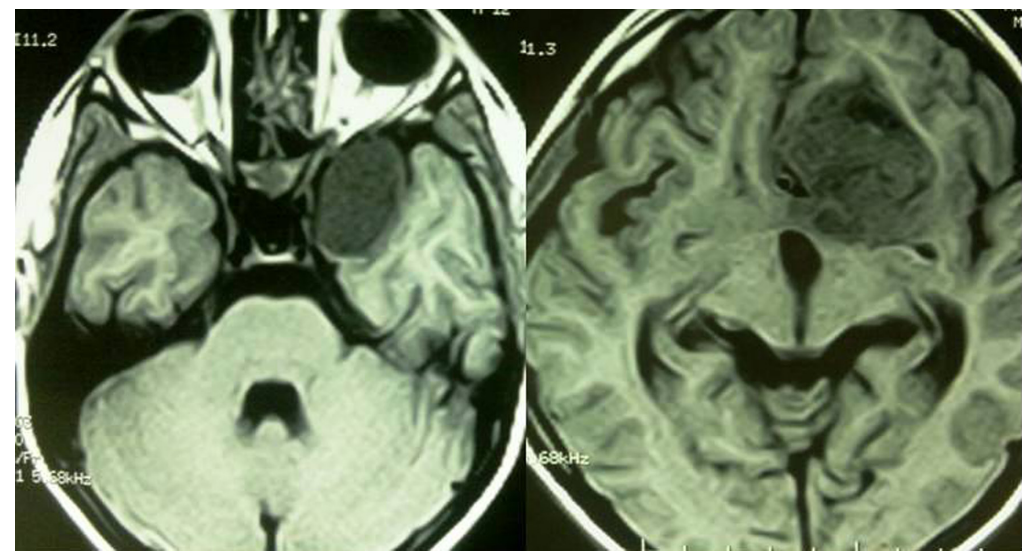

Figure 2. Axial T1 weighted MRI images reveal a heterogeneously solid hypointense mass with a cystic component in the sellar/suprasellar region.

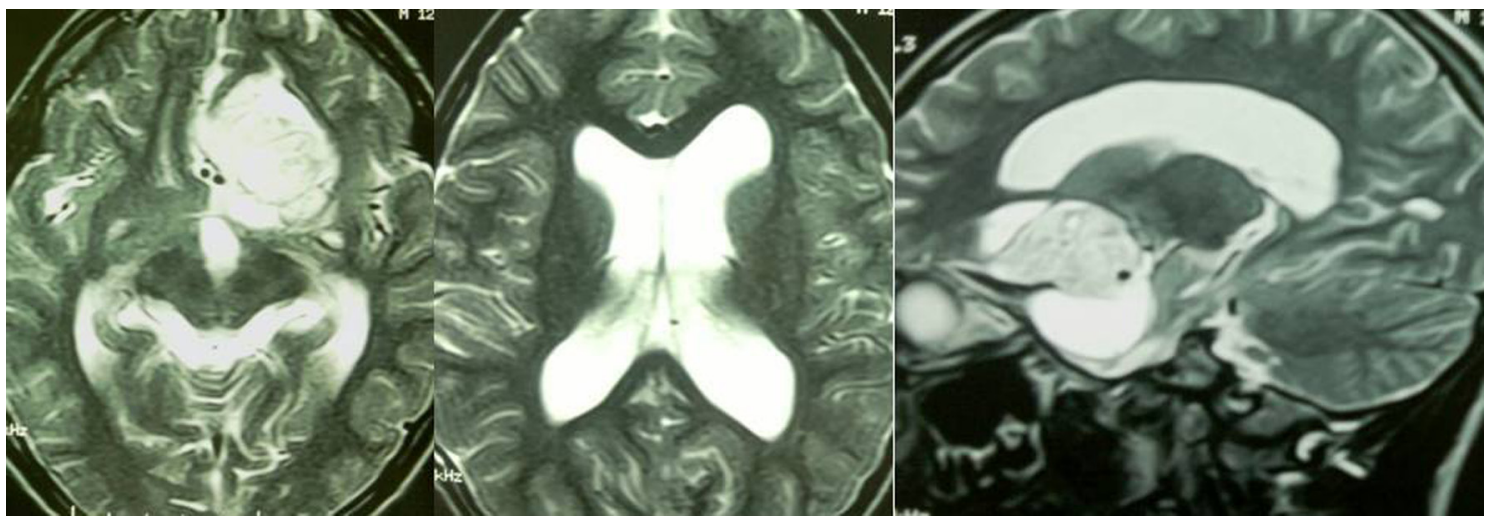

Figure 3. Axial and Sagittal T2 weighted MRI images reveal a heterogeneously solid hyperintense mass with cystic component in the sellar/suprasellar region with associated dilatation of the third and lateral ventricles.

\section{Discussion}

Pilocytic astrocytoma, previously known as spongioblas- toma, is a histologic subtype of astrocytoma, classified as WHO Grade I, with a rather benign, slow-growing biological behaviour. This tumor occurs most commonly in children 


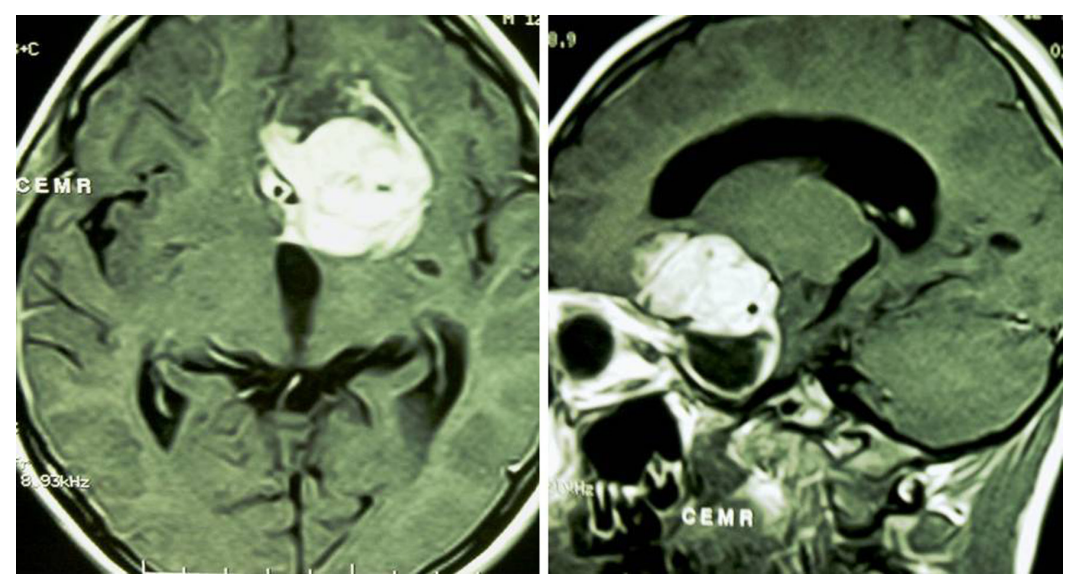

Figure 4. Post Contrast Axial and Sagittal T1 weighted images reveal intense homogeneous enhancement of the lesion with a non enhancing cyst.

and young adults. Most patients present before the age of 20 years. Only about $25 \%$ of patients are older than 18 years, and less than $17 \%$ are older than 30 years [4]. Among the various age groups of patients with pilocytic astrocytoma, the major location of tumor differs in prevalence. In children, up to $67 \%$ of patients present with cerebellar lesions, whereas in adults, about $55 \%$ of patients present with supratentorial lesions [5].

The most common clinical features of pilocytic astrocytomas include headache, nausea, vomiting, seizure, ataxia, and visual abnormality, depending on the tumor location $[5,6]$. Headache, vomiting, gait disturbance, blurred vision, diplopia, and neck pain are common symptoms in patients with a cerebellar pilocytic astrocytoma. Clinical signs usually include hydrocephalus, papilledema, truncal ataxia, ap-

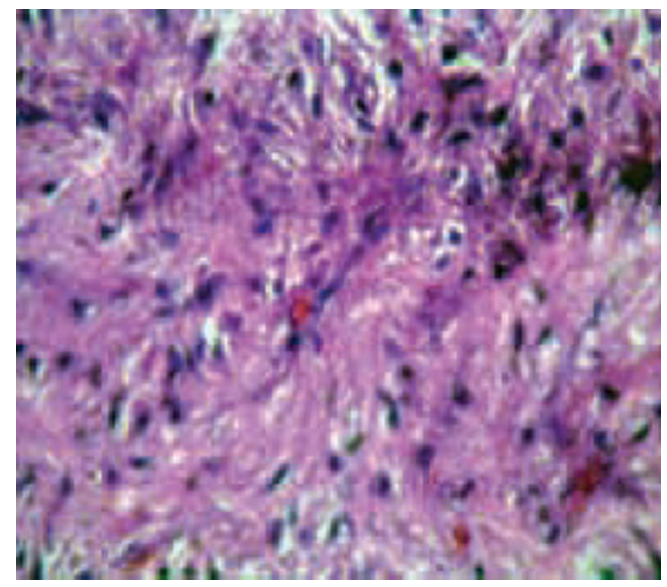

Figure 5. Histological Slide (haematoxylin-eosin, magnification $100 \times$ ) confirming the diagnosis of pilocytic astrocytoma: biphasic pattern showing a combination of loose glial tissue and compact piloid tissue with elongated bipolar cells showing fibrillary hair-like processes, in addition to Rosenthal fibres. pendicular dysmetria, head tilt, sixth nerve palsy and nystagmus. When a pilocytic astrocytoma arises in the brainstem, it typically extends exophytically from its dorsal margin and causes symptoms of nausea, vomiting, and ataxia, with evidence of torticollis, papilledema, nystagmus, and palsies of the sixth and seventh cranial nerves at physical examination. Pilocytic astrocytoma of the optic pathway frequently produces visual loss or visual-field deficit, with optic disk pallor and optic nerve atrophy in the involved eye secondary to axonal damage and ischemia [7, 8]. Pilocytic astrocytoma of the hypothalamus may produce symptoms related to obesity, diabetes insipidus, and other symptoms of hypothalamicpituitary dysfunction [9]. Headache, seizure activity, hemiparesis, ataxia, nausea, and vomiting are common clinical manifestations for pilocytic astrocytomas arising in the cerebral hemispheres.

Grossly, the tumors are cystic, with mural nodules in $50 \%$, and more solid with various cystic central cavities in $40 \%$ [10]. Completely solid tumours comprise only $10 \%$ of the total. On CT scan the tumour matrix appears hypodense or isodense and enhances strongly. On MRI, pilocytic astrocytomas are hypointense on $\mathrm{T} 1$ and hyperintense on $\mathrm{T} 2$, proton density, and FLAIR images. The cystic component appears hypointense on $\mathrm{T} 1$ and hyperintense on $\mathrm{T} 2$ weighted images. Strong homogeneous contrast enhancement of the solid component is seen. Macrocysts tend to occur in cerebral and cerebellar lesions and rarely in the lesions along the optic pathway or around the third ventricle [11]. Such lesions appear predominantly solid on CT and MRI scans.

Histologically, juvenile pilocytic astrocytoma is composed of distinct areas of compact pilocytic astrocytes, mostly arranged around vessels, and mixed with areas having looser, protoplasmic, or partially cystic appearance [12]. This gives a definite biphasic appearance to the tumour when viewed under low power magnification. Tumour calcification which occurs rarely tends to be fleck like [11]. Only a 
minority of pilocytic astrocytomas undergoes calcification suggesting chronicity of the lesion [13].

In our case, an ill defined intensely enhancing heterogeneously solid mass with a small cystic component in the sellar/suprasellar region was seen with dense calcifications which were readily apparent on CT scans. A provisional diagnosis of craniopharyngioma was given at that time which later on proved to be an extensively calcified pilocytic astrocytoma on histopathological examination.

\section{Conclusion}

We conclude that although quite rare, dense calcifications may occur in pilocytic astrocytomas and so pilocytic astrocytoma must always be kept in differential diagnosis of strongly enhancing solid or solid cystic sellar/suprasellar masses with calcification in adolescent age group.

\section{Conflict of Interest}

Authors declare no conflict of interest.

\section{Abbreviations}

WHO: World Health Organisation

CT: Computed Tomography

MRI: Magnetic Resonance Imaging

\section{References}

1. Scheithauer B.W, Hawkins C, Tihan T, Vanden-Berg S.R, Burger P.C: Pilocytic astrocytoma. In: Louis DN, Ohgaki H, Wiestler OD, Cavenee WK WHO Classification of Tumours of the Central Nervous System, 4th edn. Lyon, France. IARC Press. 2007; pp 14-21.

2. Rosemberg S, Fujiwara D. Epidemiology of pediatric tumors of the nervous system according to the WHO
2000 classification: a report of 1,195 cases from a single institution. Childs Nerv Syst. 2005;21(11):940-944.

3. Dirven CM, Mooij JJ, Molenaar WM. Cerebellar pilocytic astrocytoma: a treatment protocol based upon analysis of 73 cases and a review of the literature. Childs Nerv Syst. 1997;13(1):17-23.

4. Li HM, Hsu SS, Wang JS, Weng MJ, Fu JH, Chen CK, Lai PH. Cerebral pilocytic astrocytoma with spontaneous intracranial hemorrhage in adults. J Chin Med Assoc. 2008;71(11):587-593.

5. Brown PD, Buckner JC, O'Fallon JR, Iturria NL, Brown CA, O'Neill BP, Scheithauer BW, et al. Adult patients with supratentorial pilocytic astrocytomas: a prospective multicenter clinical trial. Int J Radiat Oncol Biol Phys. 2004;58(4):1153-1160.

6. Clark GB, Henry JM, McKeever PE. Cerebral pilocytic astrocytoma. Cancer. 1985;56(5):1128-1133.

7. Dutton JJ. Gliomas of the anterior visual pathway. Surv Ophthalmol. 1994;38(5):427-452.

8. Roh S, Mawn L, Hedges TR, 3rd. Juvenile pilocytic astrocytoma masquerading as amblyopia. Am J Ophthalmol. 1997;123(5):692-694.

9. Burger PC, Scheithauer BW, Paulus W, Szymas J, Giannini C, Kleihues P. Pilocytic astrocytoma. In: Kleihues P, Cavenee W, eds. Pathology and genetics of tumours of the nervous system. Lyon, France: IARC, 2000; 45-51.

10. Coakley KJ, Huston J, 3rd, Scheithauer BW, Forbes G, Kelly PJ. Pilocytic astrocytomas: well-demarcated magnetic resonance appearance despite frequent infiltration histologically. Mayo Clin Proc. 1995;70(8):747-751.

11. Lee YY, Van Tassel P, Bruner JM, Moser RP, Share JC. Juvenile pilocytic astrocytomas: CT and MR characteristics. AJR Am J Roentgenol. 1989;152(6):1263-1270.

12. Garcia DM, Fulling KH. Juvenile pilocytic astrocytoma of the cerebrum in adults. A distinctive neoplasm with favorable prognosis. J Neurosurg. 1985;63(3):382-386.

13. Burger PC, Scheithauer BW, Vogel FS: The brain tumors. In: Surgical Pathology of the Nervous System and its Coverings, Churchill Livingstone, New York, 2002, pp.160-378. 